\title{
Aldol condensations of a variety of different aldehydes and ketones under ultrasonic irradiation using poly ( $N$-vinylimidazole) as a new heterogeneous base catalyst under solvent-free conditions in a liquid-solid system
}

\author{
Nader Ghaffari Khaligh a,*, Taraneh Mihankhah ${ }^{\mathrm{b}}$ \\ a House Research of Professor Reza. Education Guilan, Rasht, District 1, 41569-17139, Iran \\ ${ }^{\mathrm{b}}$ Department of Civil Engineering, Noshirvani of University of Technology, Babol, 47148-71167, Iran
}

\section{A R T I C L E I N F O}

\section{Article history:}

Received 24 June 2013

Accepted 11 July 2013

Published 20 December 2013

\section{Keywords:}

Ultrasound-assisted reaction

Liquid-solid system

Poly( $N$-vinylimidazole)

Aldol condensation

Solvent-free

\begin{abstract}
A B S T R A C T
An ultrasound-assisted aldol condensation reaction has been developed for a range of ketones with a variety of aromatic aldehydes using poly ( $N$-vinylimidazole) as a solid base catalyst in a liquid-solid system. The catalyst can be recovered by simple filtration and reused at least 10 times without any significant reduction in its activity. The reaction is also amenable to the large scale, making the procedure potentially useful for industrial applications.
\end{abstract}

(C) 2013, Dalian Institute of Chemical Physics, Chinese Academy of Sciences. Published by Elsevier B.V. All rights reserved.

tion [3-7].

Ultrasound-assisted organic synthesis (UAOS) is a green synthetic technique that has grown in popularity during the past two decades and is applicable to a variety of practical syntheses. There are several notable features to UAOS, including enhanced reaction rates, improved levels of selectivity, higher product yields and purity, and facile manipulation. Furthermore, UAOS can be considered as a processing aid in terms of energy conservation and waste minimization compared with traditional methods, and represents a chemistry platform that is much more amenable to the implementation of green chemistry concepts [8-14]. We recently described a series of different syntheses that were catalyzed by new solid acid catalysts under ultrasound irradiation conditions, including the synthesis of 14-aryl-14H-dibenzo[a,j]xanthenes [15], a one-pot synthesis of substituted coumarins [16], and the chemoselective

*Corresponding author. Tel: +98-21-66431738; Fax: +98-21-66934046; E-mail: ngkhaligh@gmail.com, ngkhaligh@guilan.ac.ir DOI: 10.1016/S1872-2067(12)60658-5 | http://www.sciencedirect.com/science/journal/18722067 | Chin. J. Catal., Vol. 34, No. 12, December 2013 
1,1-diacetate protection and deprotection of aldehydes [17]. The use of ultrasound in heterocyclic system, however, remains relatively unexplored [18].

The aldol condensation reaction is one of the most fundamental and important $\mathrm{C}-\mathrm{C}$ bond forming reactions in organic synthesis [19-28]. Based on the importance of the methylene moiety, which is found in many naturally occurring compounds and antibiotics, and the use of $\alpha, \alpha^{\prime}$-bis(substituted benzylidene) cycloalkanones as precursors for the synthesis of bioactive pyrimidine derivatives [29], we were particularly interested in the condensation of cycloalkanones with aldehydes and ketones, and the cross-aldol condensation reactions represent an effective way in which to access these materials. These reactions are usually catalyzed by strong acids or bases, and a variety of different Lewis acids have been evaluated in this reaction [30]. Although chalcones are traditionally prepared by the base catalyzed Claisen-Schmidt condensation [31] of arylaldehydes and acetophenones, acid-catalyzed [32,33], solid- [34] and resin-supported [35], and microwave-assisted [36] versions of the condensation reaction have also been reported in the literature. There have also been reports in the literature involving condensation reactions under ultrasound irradiation conditions that were catalyzed by inorganic bases [37-40]. Unfortunately, the presence of a strong acid or base promotes the reverse reaction [41], and this can lead to the self-condensation of the starting materials to give the corresponding byproducts in low yields [42].

The practical applications of poly( $N$-vinylimidazole) (PVIm) are wide and varied, ranging from dyestuffs, catalysts, corrosion inhibitors, and ion exchange resins to their application in quenching media and metal ion complexation reactions [43]. $N$-Methylimidazole has been used as a Lewis base catalyst for the aldol condensation reactions of trimethylsilyl enolate with a range of different aldehydes [44,45].

In a continuation of our ongoing research towards the development of new catalysts and methods for organic synthesis [46-52], we recently used PVIm as an efficient solid Lewis base catalyst for the $\mathrm{N}$-Boc protection of amines as well as the acetylation of alcohols, phenols, thiols, and amines under solvent-free conditions [53,54]. To expand the application of ultrasound for the synthesis of heterocyclic compounds, herein we report the use of PVIm as a catalyst for the aldol condensation reaction of ketones with aldehydes under ultrasound irradiation and solvent-free conditions in liquid-solid media (Scheme 1). Pleasingly, this method provided access to the corresponding $\alpha, \beta$-unsaturated ketones in high yields, and the catalyst could be readily separated from the reaction mixture and reused several times without any significant impact on its activity.

\section{Experimental}

\subsection{Materials}

Unless specified otherwise, all of the chemicals used in the current study were purchased as the analytical grades from Merck, Aldrich, or Fluka and used without further purification. The products were characterized on the basis of their physical data and a comparison with authentic samples. The reactions and substrate purity levels were monitored by TLC using silica gel SIL G/UV 254 plates.

\subsection{Instrumentation}

The Fourier transform infrared (FT-IR) spectra were recorded on a Perkin Elmer 781 spectrophotometer using $\mathrm{KBr}$ pellets for solid samples in the range of $4000-400 \mathrm{~cm}^{-1}$. Liquid samples were evaluated as neat samples by IR under the same conditions. Mass spectra were recorded on a Finnigan MAT 8430 mass spectrometer operating at an ionization potential of $70 \mathrm{eV}$. In all the cases, the ${ }^{1} \mathrm{H}$ NMR spectra were recorded on a Bruker Avance 400 or $300 \mathrm{MHz}$ instrument. All of the chemical shifts have been quoted in parts per million (ppm) relative to TMS in a deuterated solvent. Microanalyses were performed on a Perkin-Elmer 240-B microanalyzer. Melting points were recorded on a Büchi B-545 apparatus in open capillary tubes. A Shanghai Branson-CQX ultrasonic cleaner with a frequency of $25 \mathrm{kHz}$ and a nominal power $250 \mathrm{~W}$, and Bandelin Sonorex ultrasonic bath with built-in heating $\left(30-80^{\circ} \mathrm{C}\right)$, a frequency of $35 \mathrm{kHz}$, and a nominal power $200 \mathrm{~W}$, were used for the ultrasonic irradiation.

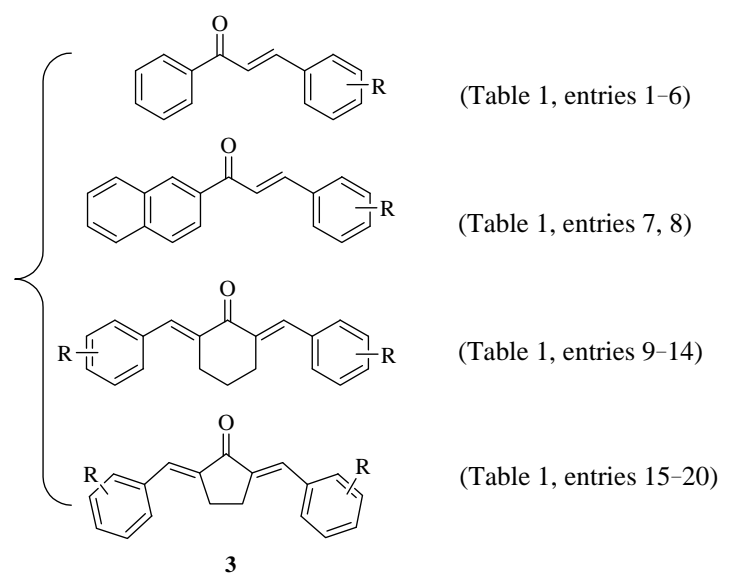

Scheme 1. Aldol condensation of ketones with aldehydes. 


\subsection{Preparation of PVIm}

PVIm was synthesized using a standard free-radical polymerization process as previously reported [55,56]. The polymer was precipitated as a white powder and collected by filtration before being dried at $40{ }^{\circ} \mathrm{C}$. The PVIm was purified by a process of dissolution in methanol and subsequent precipitation from acetone, with the process being performed twice. The polymer was then dialyzed against distilled water using dialysis tubing before being isolated by lyophilization and dried over $\mathrm{P}_{4} \mathrm{O}_{10}$ in vacuo at ambient temperature. The molecular weight of the PVIm sample was determined by viscometry using the Mark-Houwink-Sakurada equation, as follows, using parameters taken from the literature [57]: $[\mu]=K\left(M_{\mathrm{v}}\right)^{a}$, where $K=122$ $\times 10^{-3} \mathrm{~mL} / \mathrm{g}$ and $a=0.51$ in $0.1 \mathrm{~mol} / \mathrm{L} \mathrm{NaCl}$ at $25^{\circ} \mathrm{C}$. The $M_{\mathrm{v}}$ value of PVIm was found to be $305000 \mathrm{~g} / \mathrm{mol}$.

\subsection{General procedure for aldol condensation in a liquid/solid system under refluxing conditions}

Benzaldehyde (10 mmol) was slowly added to a magnetically stirred suspension of acetophenone $(12 \mathrm{mmol})$ and PVIm $(50 \mathrm{mg})$ in a round-bottomed flask $(25 \mathrm{~mL})$ equipped with a condenser, and the resulting mixture was stirred at reflux for 4 $\mathrm{h}$. The reaction mixture was then cooled to ambient temperature and diluted with $\mathrm{CH}_{2} \mathrm{Cl}_{2}(20 \mathrm{~mL})$ before being filtered to allow for the recovery of the catalyst. The filtrate was then collected and the solvent was removed under reduced pressure to give the crude product as a residue, which was purified by silica gel column chromatography using a mixture of ethyl acetate (EtOAc) and petroleum ether $(2: 8, \mathrm{v} / \mathrm{v})$ as the eluent to give the $\alpha, \beta$-unsaturated ketone (Chalcone).

\subsection{General procedure for aldol condensation in a liquid/solid system under ultrasound irradiation}

A mixture of acetophenone (12 mmol), benzaldehyde (10 mmol), and PVIm (50 mg) in a round-bottom flask was irradiated in a Shanghai Branson-CQX ultrasonic apparatus (with a frequency of $25 \mathrm{kHz}$ and a nominal power $250 \mathrm{~W}$ ) at ambient temperature for $40 \mathrm{~min}$. A portion of $\mathrm{CH}_{2} \mathrm{Cl}_{2}(20 \mathrm{~mL})$ was then added to the reaction and the resulting mixture was filtered to allow for the recovery of the catalyst. The filtrate was then collected and the solvent removed in vacuo to give the crude product as a residue, which was purified by silica gel column chromatography using a mixture of EtOAc and petroleum ether $(2: 8, v / v)$ as an eluent to give the desired chalcone. The chalcones were then crystallized from hot methanol prior to their analysis and the determination of their meting points [58-67].

Chalcone (Table 2, entry 1). $\mathrm{mp} 55-57^{\circ} \mathrm{C}$; IR (KBr) $v=3230$, 2931, 1830, 1730, 1655, 1287, 753, $682 \mathrm{~cm}^{-1}$; ${ }^{1} \mathrm{H}$ NMR $(300$ $\left.\mathrm{MHz} \mathrm{CDCl}_{3}\right) \delta=6.12(\mathrm{~d}, J=16.0 \mathrm{~Hz}, 1 \mathrm{H}), 7.25(\mathrm{~d}, J=16.0 \mathrm{~Hz}$, 1H), 7.09-7.30 (m, 5H), 7.39-7.93 (m, 5H); MS (EI) $m / z=208$ $\left[\mathrm{M}^{+}\right]$.

1-Naphthalen-2-yl-3-tolyl-propenone (Table 2, entry 8). mp 140-142 ${ }^{\circ} \mathrm{C}$; IR (KBr) $v=3011,2910,1649,1600,1554,1174$, 978, 805, $746 \mathrm{~cm}^{-1} ;{ }^{1} \mathrm{H}$ NMR $\left(300 \mathrm{MHz}, \mathrm{CDCl}_{3}\right) \delta=3.37(\mathrm{~s}, 3 \mathrm{H})$,
8.13-7.27 (m, 13H); MS (EI) $m / z=272\left[\mathrm{M}^{+}\right]$.

2,6-Di(p-methoxybenzylidene)cyclohexanone (Table 2, entry 12). mp 200-201 ${ }^{\circ} \mathrm{C}$; IR (KBr) $v=3020,2922,1655,1600$, 1147, $780 \mathrm{~cm}^{-1}$; ${ }^{1} \mathrm{H}$ NMR (300 MHz, $\left.\mathrm{CDCl}_{3}\right) \delta=1.79-1.85(\mathrm{~m}$, 2H), $2.95(\mathrm{t}, J=6.0 \mathrm{~Hz}, 4 \mathrm{H}), 3.82(\mathrm{~s}, 6 \mathrm{H}), 6.91-7.40(\mathrm{~m}, 8 \mathrm{H}), 7.77$ (s, 2H); MS (EI) $m / z=334\left[\mathrm{M}^{+}\right]$.

2,6-Di(p-nitrobenzylidene)cyclopentanone (Table 2, entry 19). mp 232-234 ${ }^{\circ} \mathrm{C}$; IR (KBr) $v=3105,2852,1705,1602$, $1525,1344,821 \mathrm{~cm}^{-1}$; ${ }^{1} \mathrm{H}$ NMR $\left(300 \mathrm{MHz}, \mathrm{CDCl}_{3}\right) \delta=3.07(\mathrm{~s}$, $4 \mathrm{H}), 7.62-8.10(\mathrm{~m}, 8 \mathrm{H}), 8.28(\mathrm{~s}, 2 \mathrm{H})$; MS (EI) $m / z=350\left[\mathrm{M}^{+}\right]$.

\subsection{General procedure for catalyst recycling in a liquid/solid system}

A mixture of the polymeric reagent $(1.0 \mathrm{~g})$ collected from different experiments was washed several times with cold ethanol and then dried at ambient temperature for $12 \mathrm{~h}$ under vacuum. The resulting catalyst was then considered to be ready for further runs. Experimental results revealed that the PVIm could be effectively recovered from the reaction mixture during the work-up procedure. The recovery in most cases was 100\%, with no discernible changes detected in the catalytic activity of the PVIm.

\section{Results and discussion}

Before evaluating the scope of the current ultrasonic irradiation reaction, we endeavored to optimize the reaction conditions in terms of the yield and reaction time by investigating the impact of several different reaction parameters, including the reaction solvent, temperature, and catalyst loading. Our initial investigations focused on the PVIm catalyzed aldol condensation of benzaldehyde with acetophenone as a model reaction. When the condensation reaction was conducted in different organic solvents, including ethanol, acetonitrile, dichloromethane, and toluene, a mixture of products was obtained in poor to moderate yields. The rate and yield of the condensation reaction were determined to be dependent on the type of solvent with a preference for the use of polar solvents (Table 1).

Increases in the reaction temperature led to increases in the rate of the condensation reaction and gave higher yields of the desired products (Table 1). When the PVIm catalyzed reaction was performed in refluxing solvents, however, no significant improvements in the yield were observed. The use of different solvents, with the exception of ethanol and acetonitrile, led to lower yields of the product. These results suggested that the lower yields observed in polar solvents were not necessarily related to the polarity of the solvent. When a mixture of benzaldehyde and acetophenone was stirred in ethanol or acetonitrile for $16 \mathrm{~h}$ at reflux in the presence of PVIm, chalcone was produced in $96 \%$ or $88 \%$ yield, respectively.

It is noteworthy that solvent-free conditions were required in several cases to allow for the desired products to be obtained in practically useful yields, because the use of organic solvents in these cases had a severe adverse impact on the rate of the processes and made them practically unfeasible. The results of these experiments revealed that the highest yield for the model 


\section{Table 1}

Effect of different solvents on the reaction of acetophenone with benzaldehyde at ambient temperature and refluxing conditions in the presence of catalytic PVIm.

\begin{tabular}{|c|c|c|c|}
\hline Entry & Solvent & Condition & Yield $^{\mathrm{a}}(\%)$ \\
\hline \multirow[t]{2}{*}{1} & Dichloromethane & r.t. & 35 \\
\hline & & reflux & 42 \\
\hline \multirow[t]{2}{*}{2} & Dichloroethane & r.t. & 33 \\
\hline & & reflux & 37 \\
\hline \multirow[t]{2}{*}{3} & Toluene & r.t. & 12 \\
\hline & & reflux & 20 \\
\hline \multirow[t]{2}{*}{4} & Methanol & r.t. & 11 \\
\hline & & reflux & 14 \\
\hline \multirow[t]{2}{*}{5} & Ethanol & r.t. & 30 \\
\hline & & reflux & 44 \\
\hline \multirow[t]{2}{*}{6} & Acetonitrile & r.t. & 32 \\
\hline & & reflux & 40 \\
\hline \multirow[t]{2}{*}{7} & Solvent-free ${ }^{b}$ & r.t. & 69 \\
\hline & & $50^{\circ} \mathrm{C}$ & 71 \\
\hline
\end{tabular}

Reaction conditions: PVIm $5 \mathrm{mg}$, benzaldehyde $1 \mathrm{mmol}$, acetophenone $1.2 \mathrm{mmol}$, different solvents $5 \mathrm{~mL}, 4 \mathrm{~h}$.

a Isolated yield.

b Reaction conditions: PVIm $50 \mathrm{mg}$, benzaldehyde $10 \mathrm{mmol}$, acetophenone $12 \mathrm{mmol}, 4 \mathrm{~h}$.

reaction was obtained under solvent-free conditions (Table 1, entry 7). When the amount of PVIm added to the reaction was 5 $\mathrm{mg}$ with respect to the charge of the benzaldehyde $(10 \mathrm{mmol})$, the yield of the chalcone was found to be $69 \%$ within $4 \mathrm{~h}$ at ambient temperature under solvent-free conditions. Further increasing the reaction temperature to $50{ }^{\circ} \mathrm{C}$ provided no obvious improvement in the yield (Table 1, entry 7). Furthermore, increases in the reaction temperature led to a deterioration in the purity profile of the reaction, with more byproducts being formed.

We then proceeded to investigate the loading of the catalyst for the transformation using loadings in the range of 5 to $50 \mathrm{mg}$ of catalyst for $10 \mathrm{mmol}$ of benzaldehyde. A control experiment was also conducted in the absence of the PVIm catalyst at ambient temperature and revealed that none of the desired product was formed under the solvent-free conditions even when the reaction time was extended to $24 \mathrm{~h}$. This result therefore highlighted the importance of the PVIm catalyst. Increasing the amount of PVIm to 10,25 , and $50 \mathrm{mg} / 10 \mathrm{mmol}$ benzaldehyde led to increases in the yield of the chalcone to $77 \%, 85 \%$, and $94 \%$ within $4 \mathrm{~h}$, respectively. The results also revealed that the catalytic activity of the PVIm catalyst increased when the loading was increased from 5 to $50 \mathrm{mg}$, with the yield of the chalcone increasing from $69 \%$ to $94 \%$. The activity of the catalyst was found to be directly proportional to the number of active basic sites available for the reactants. The basicity of the PVIm is derived predominantly from the free imidazole moieties attached to the backbone of PVIm polymer. For the reactions conducted over a range of different PVIm loadings (from low to high), the number of active basic sites increased in a linear manner, and this was directly reflected by increases in the yield of the chalcone. To achieve efficient stirring, we found that the loading of the catalyst could not exceed $30 \mathrm{mg}$ (with respect to $10 \mathrm{mmol}$ benzaldehyde). More concentrated reaction mixtures were simply too viscous to be stirred effectively with magnetic or mechanical stirring equipment. The failure of these different stirring methods is what prompted us to investigate the use of sonication as a way in which to achieve more efficient levels of mixing at higher reaction concentrations. Pleasingly, at a catalyst loading of $50 \mathrm{mg}$ combined with sonication, the model reaction gave the desired chalcone in $94 \%$ of yield in $40 \mathrm{~min}$. Further increases in the sonication time did not lead to increases in the yield. In comparison, when the reaction was conducted under solvent-free conditions without ultrasonic irradiation at ambient temperature, a reaction time of $4 \mathrm{~h}$ was required to provide a yield of $94 \%$. The use of ultrasound therefore clearly accelerated the synthesis of the chalcone. The chemical effects of ultrasounds have been attributed to the implosive collapse of the cavitations produced by the sound waves. The cavitation process itself is associated with the formation of bubbles having dynamic life under ultrasonic irradiation conditions. These bubbles are generated at localized sites in the liquid mixture that contain small amounts of dissolved gases. The bursting of these bubbles results in high temperatures and pressures that can facilitate intermolecular reactions. When one of the phases is a solid, such as the catalyst or the substrate, ultrasonic irradiation can have several additional enhancing effects, and this can be especially useful when the solid acts as a catalyst [68]. The cavitation effect can lead to the formation of microjects of acetophenone that can bombard the surface of the solid base (PVIm). This in turn can lead to an increase in the number of exposed sites on the unreacted surface of the PVIm and enhance the overall reactivity of the interphase surface [69]. The ultrasound technique has been shown to represent a more effective procedure than standard stirring techniques in terms of providing higher yields and requiring milder reaction conditions and shorter reaction times.

The effect of different irradiation frequencies on the reaction was also investigated. When the frequency of ultrasound irradiation was $25 \mathrm{kHz}$, the yield of the chalcone was $94 \%$ within $40 \mathrm{~min}$, whereas the use of a frequency of $35 \mathrm{kHz}$ provided a yield of $84 \%$ in the same time. The use of a lower frequency of ultrasound irradiation appeared to provide higher yields of the chalcone, likely because the use of a higher ultrasonic frequency would lead to a reduction in the production of cavitations in the liquids [70,71].

With the optimized reaction conditions in hand, we proceeded to define the scope and limitations of this new methodology by subjecting a variety of different aromatic aldehydes to the aldol condensation with a range of different ketones under the optimized conditions. The results are summarized in Table 2. Pleasingly, the results revealed that the current method was quite general and particularly effective for the synthesis of chalcones and $\alpha, \alpha^{\prime}$-bis(substituted benzylidene) cycloalkanones. Furthermore, the reaction conditions were sufficiently mild enough not to induce any damage to sensitive moieties such as the methoxy group (Table 2, entries 4,12, and 18), which can often undergo cleavage in the presence of strong acids or certain Lewis acids. Table 2 shows that significant differences were observed in the reaction times of different substrates. For example, aromatic aldehydes bearing electron-withdrawing substituents (Table 2, entries 5, 13 and 19) 
Table 2

Synthesis of chalcone and $\alpha, \alpha^{\prime}$-bis(substituted) benzylidene cyclopentanone and cyclohexanones derivatives in the presence PVIm under ultrasonic conditions. ${ }^{\text {a }}$

\begin{tabular}{|c|c|c|c|c|c|c|}
\hline \multirow{2}{*}{ Entry } & \multirow{2}{*}{ Ketone } & \multirow{2}{*}{$\mathrm{R}$} & \multirow{2}{*}{ Time (min) } & \multirow{2}{*}{ Yield b (\%) } & \multicolumn{2}{|c|}{ Melting point $\left({ }^{\circ} \mathrm{C}\right)$} \\
\hline & & & & & Found & Reported \\
\hline 1 & Acetophenone & $\mathrm{H}$ & 40 & 94 & $55-57$ & $55-57[58]$ \\
\hline 2 & & 4-Cl & 40 & 92 & $112-114$ & $114-115[58,59]$ \\
\hline 3 & & 4-Me & 25 & 94 & 98-99 & $98-99[58]$ \\
\hline 4 & & 4-MeO & 60 & 90 & $75-76$ & $75-76[58]$ \\
\hline 5 & & $4-\mathrm{NO}_{2}$ & 20 & 94 & $154-156$ & $158-159[58,60]$ \\
\hline 6 & & Cinnamaldehyde & 40 & 92 & $105-106$ & 103-104 [60] \\
\hline 7 & 2-Acetonaphthone ${ }^{\mathrm{c}}$ & $4-\mathrm{Cl}$ & 60 & 93 & $164-167$ & $162-164[59]$ \\
\hline 8 & & 4-Me & 40 & 96 & $140-142$ & $143-145$ [59] \\
\hline 9 & Cyclohexanone ${ }^{\mathrm{d}}$ & $\mathrm{H}$ & 40 & 93 & $115-117$ & $116-117[61,62]$ \\
\hline 10 & & $4-\mathrm{Cl}$ & 40 & 92 & $143-145$ & $147-148$ [63-65] \\
\hline 11 & & $4-\mathrm{Me}$ & 40 & 91 & $172-174$ & $170[64-66]$ \\
\hline 12 & & 4-MeO & 55 & 92 & $200-201$ & $203-204[61,62,64]$ \\
\hline 13 & & $4-\mathrm{NO}_{2}$ & 25 & 90 & $156-157$ & $158-159[61,62,64]$ \\
\hline 14 & & Cinnamaldehyde & 40 & 95 & $176-178$ & $179[61,62,64]$ \\
\hline 15 & Cyclopentanone $\mathrm{d}^{\mathrm{d}}$ & $\mathrm{H}$ & 40 & 93 & $190-191$ & $188-189[61,62,64]$ \\
\hline 16 & & 4-Cl & 40 & 92 & $230-232$ & $225[59,61]$ \\
\hline 17 & & 4-Me & 25 & 96 & $216-218$ & $218-220[59,61,67]$ \\
\hline 18 & & 4-MeO & 40 & 91 & $208-210$ & $210-211[61,62,64]$ \\
\hline 19 & & $4-\mathrm{NO}_{2}$ & 30 & 90 & $232-234$ & $230-231[61,62,64]$ \\
\hline 20 & & Cinnamaldehyde & 40 & 93 & $220-221$ & $223[61,62,64]$ \\
\hline
\end{tabular}

a All of the products were characterized on the basis of their physical data and through a comparison with authentic samples [58-67].

$\mathrm{b}$ Isolated yields.

c 2 -Acetonaphthone is a solid at room temperature with a melting point in the range of $53-55^{\circ} \mathrm{C}$. Under ultrasonic conditions, however, this material appeared to melt at ambient temperature.

${ }^{\mathrm{d}}$ Reaction conditions: PVIm $50 \mathrm{mg}$, cyclohexanone or cyclopentanone $10 \mathrm{mmol}$, an aldehyde 20 mmol, under ultrasonic.

underwent the reaction at a much faster rate than aromatic aldehydes bearing electron-donating groups (Table 2, entries 4, 12, and 18).

The reusability of solid Lewis base PVIm catalyst was evaluated using the aldol condensation of acetophenone with benzaldehyde in the presence of recycled PVIm. This reaction gave isolated yields of the chalcone in the yield of 94\%-91\% following ten runs with the recycled catalyst, and clearly demonstrated the practical recyclability of the catalyst (Table 3).

Interestingly, we were able to conduct the synthesis of chalcone on a larger scale without any difficulty by using only $50 \mathrm{mg}$ of PVIm under ultrasound irradiation conditions. The reaction of acetophenone (30 mmol) was investigated with benzaldehyde ( $25 \mathrm{mmol}$ ) in the presence of PVIm ( $50 \mathrm{mg}$ ), and

Table 3

Reusability of PVIm for the synthesis of chalcone.

\begin{tabular}{lcc}
\hline Run & Time (min) & Isolated yield (\%) \\
\hline 1 & 40 & 94 \\
2 & 40 & 93 \\
3 & 40 & 94 \\
4 & 40 & 94 \\
5 & 40 & 93 \\
6 & 40 & 93 \\
7 & 42 & 93 \\
8 & 42 & 93 \\
9 & 44 & 93 \\
10 & 44 & 92 \\
\hline
\end{tabular}

Reaction conditions: PVIm $50 \mathrm{mg}$, benzaldehyde $10 \mathrm{mmol}$, acetophenone 12 mmole under ultrasonic irradiation at room temperature. the desired product was isolated in $85 \%$ yield within $40 \mathrm{~min}$, indicating that a large-scale reaction was also feasible using an efficient quantity of PVIm.

We have proposed a mechanism for the current transformation as shown in Scheme 2. In the first step, the microjects of acetophenone (1) would be deprotonated on the surface of solid base catalyst with the imidazole groups of the PVIm behaving as proton acceptors. The microjects of the resulting enolate compound could then condensed with aldehyde (2) to give an aldol, which would be dehydrated to give the chalcone product (3).

Some previously reported data for the reaction conditions and associated product yields for the preparation of $\alpha, \alpha$-bis(substituted benzylidene)cyclopentanone (Table 2, entry 15) were compared with our results (Table 4). The results clearly show that our newly developed conditions provide preferable results in nearly all cases in terms of the yield and reaction time.

\section{Conclusions}

We have developed an efficient and much improved procedure for the coupling reaction of acetophenone with benzaldehydes, and therefore provided facile access to a variety of different chalcone derivatives in high yield. There are several advantages to the current methodology, including: (1) the current procedure is particularly simple because the use of PVIm as a solid base catalyst does not require any inert or anhydrous conditions; (2) the reaction represents a green process because 


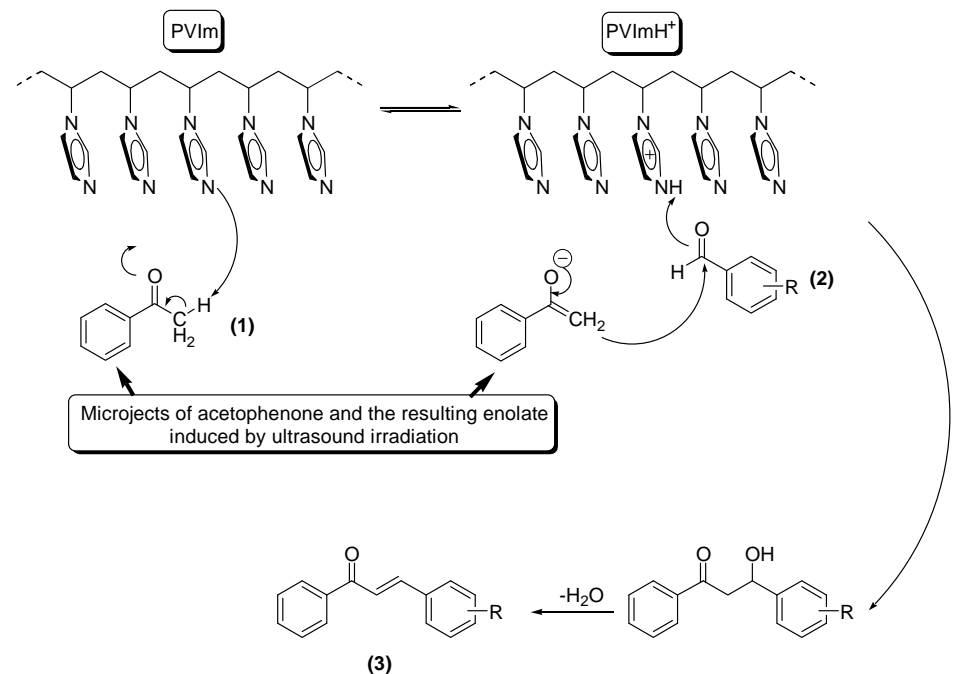

Scheme 2. Proposed mechanism for the synthesis of the chalcone derivatives.

Table 4

Comparison of the current result with those reported previously for the synthesis of $\alpha, \alpha^{\prime}$-bis(benzylidene) cyclopentanone.

\begin{tabular}{|c|c|c|c|c|c|}
\hline Entry & Catalyst & Conditions & Time (h) & Yield (\%) & Ref. \\
\hline 1 & $\mathrm{TiCl}_{3}\left(\mathrm{SO}_{3} \mathrm{CF}_{3}\right)$ & r.t., neat & 1.5 & 96 & [65] \\
\hline 2 & $\mathrm{Yb}(\mathrm{OTf})_{3}$ & $90^{\circ} \mathrm{C}$, neat & 6 & 92 & [72] \\
\hline 3 & $\mathrm{SmI}_{3}$ & THF, $\mathrm{N}_{2}$ atm., r.t. & 3 & 95 & [73] \\
\hline 4 & $\mathrm{FeCl}_{3} \cdot 6 \mathrm{H}_{2} \mathrm{O}$ & {$[\mathrm{bmim}]\left[\mathrm{BF}_{4}\right], \mathrm{TMSCl}, 80^{\circ} \mathrm{C}$} & 6 & 92 & {$[74]$} \\
\hline 5 & $\mathrm{Cu}(\mathrm{OTf})_{2}$ & $80^{\circ} \mathrm{C}$, neat & 8 & 92 & [75] \\
\hline 6 & $\mathrm{SiO}_{2}-\mathrm{R}-\mathrm{SO}_{3} \mathrm{H}$ & $90^{\circ} \mathrm{C}$, neat & 1.3 & 85 & [76] \\
\hline 7 & $\mathrm{NaOH}-\mathrm{Al}_{2} \mathrm{O}_{3}$ & $80^{\circ} \mathrm{C}$, neat & 1 & $85^{\mathrm{a}}$ & [77] \\
\hline 8 & $\mathrm{NH}_{4} \mathrm{Cl}$ & Reflux, ethanol & 5 & 93 & [78] \\
\hline 9 & Calcined $\mathrm{NaNO}_{3} / \mathrm{HAP}$ (hydroxyapatite) & r.t.; methanol & 12 & 98 & [79] \\
\hline 10 & $\mathrm{NH}_{2} \mathrm{SO}_{3} \mathrm{H}$ & Ultrasound irradiation, neat, $75-80^{\circ} \mathrm{C}$ & 0.6 & 88 & [80] \\
\hline 11 & PVIm & Ultrasound irradiation, neat, r.t. & $40 \mathrm{~min}$ & 93 & this work \\
\hline
\end{tabular}

a The synthesis of 1,3-dDiphenyl prop-2-en-1-one.

PVIm is environmentally benign; (3) the reaction is atom economical; (4) the current methodology avoids the occurrence of adverse side reactions because PVIm can facilitate the aldol condensation under mild and neutral conditions and therefore eliminate any side-reactions resulting from strong basic conditions; and (5) the catalyst can be conveniently recovered and reused without any significant impact on its activity. The current method represents an attractive alternative for the preparation of chalcones. Further work aimed at exploring this novel catalyst in other organic transformations is currently underway in our laboratory.

\section{References}

[1] Smith K. Solid Supports and Catalysis in Organic Synthesis. New York: Ellis Horwood and PTR Prentice Hall, 1992

[2] Hattori H. Chem Rev, 1995, 95: 537

[3] Curzons A, Constable C C, Cunningham V L. Clean Prod Process, 1999, 1: 82

[4] Gani R, Jiménez-Gonzalez C, ten Kate A, Crafts P A, Powell M J, Powell L, Atherton J H, Cordiner J L. Chem Eng, 2006, 113: 30

[5] Zare A, Hasaninejad A, Khalafi-Nezhad A, Moosavi-Zare A R, Beyzavi M H, Khedri F, Asadi F, Hayati N, Asifi A. J Iran Chem Soc, 2010, 7: 461

[6] Shaabani A, Ghadari R, Rahmati A, Rezayan A H. J Iran Chem Soc, 2009, 6: 710

[7] Bhosale R S, Sarda S R, Giram R P, Raut D S, Parwe S P, Ardhapure

\section{S S, Pawar R P. J Iran Chem Soc, 2009, 6: 519}

[8] Mason T J. Practical Sonochemistry. New York: Ellis Horwood, 1991

[9] Li J T, Wang S X, Chen G F, Li T S. Curr Org Synth, 2005, 2: 415

[10] Xu H, Liao W M, Li H F. Ultrason Sonochem, 2007, 14: 779

[11] Guzen K P, Guarezemini A S, Órfão A T G, Cella R, Pereira C M P, Stefani H A. Tetrahedron Lett, 2007, 48: 1845

[12] Sinha A K, Joshi B P, Sharma A, Kumar V, Acharya R. Aust J Chem, 2007, 60: 124

[13] Sinha A K, Sharma A, Joshi B P. Tetrahedron, 2007, 63: 960

[14] Kumar V, Sharma A, Sharma M, Sharma U K, Sinha A K. Tetrahedron, 2007, 63: 9718

[15] Khaligh N G. Ultrason Sonochem, 2012, 19: 736

[16] Khaligh N G, Shirini F. Ultrason Sonochem, 2013, 20: 26

[17] Khaligh N G, Shirini F. Ultrason Sonochem, 2013, 20: 19

[18] Martins M A P, Pereira C M P, Cunico W, Moura S, Rosa F A, Peres R L, Machado P, Zanatta N, Bonacorso H G. Ultrason Sonochem, 2006, 13: 364

[19] Ji S J, Wang S Y. Ultrason Sonochem, 2005, 12: 339

[20] Khosropour A R. Ultrason Sonochem, 2008, 15: 659

[21] Nagarapu L, Kantevari S, Mahankhali V C, Apuri S. Catal Commun, 2007, 8: 1173

[22] Das B, Ravikanth B, Ramu R, Laxminarayana K, Vittal-Rao B. J Mol Catal A, 2006, 255: 74

[23] Saini A, Kumar S, Sandhu J S. Synlett, 2006: 1928

[24] Ko S, Yao C F. Tetrahedron Lett, 2006, 47: 8827

[25] Madhav J V, Reddy V T, Reddy P N, Reddy M N, Kuarm S, Crooks P A, Rajitha B. J Mol Catal A, 2009, 304: 85

[26] Smith M B, March J. March's Advanced Organic Chemistry: Reac- 


\section{Graphical Abstract}

Chin. J. Catal., 2013, 34: 2167-2173 doi: 10.1016/S1872-2067(12)60658-5

Aldol condensations of a variety of different aldehydes and ketones under ultrasonic irradiation using poly( $N$-vinylimidazole) as a new heterogeneous base catalyst under solvent-free conditions in a liquid-solid system

Nader Ghaffari Khaligh *, Tarane Mihankhah

House Research of Professor Reza. Education Guilan, Iran; Noshirvani of University of Technology, Iran
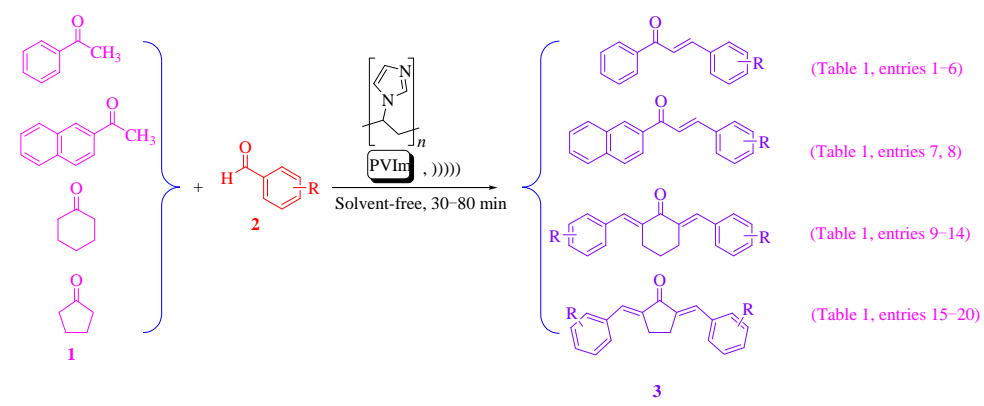

The aldol condensation reaction of a variety of different ketones with a range of aromatic aldehydes can be efficiently catalyzed in the presence of poly( $N$-vinylimidazole) (PVIm) in a liquid-solid system under ultrasonic irradiation conditions.

tions, Mechanisms, and Structure. New York: John Wiley \& Sons, 2001. 1218

[27] Norcross R D, Paterson I. Chem Rev, 1995, 95: 2041

[28] Trost B M, Fleming I. Comprehensive Organic Synthesis: 9-Volume Set. Oxford: Pergamon, 1991. Vol. 2, Parts 1.4-1.7

[29] Deli J, Lorand T, Szabo D, Foldesi A. Pharmazie, 1984, 39: 539

[30] Reeves R L. In: Patai S Ed. Chemistry of Carbonyl Group. New York: Wiley, 1966. 580

[31] Vogel A I, Tatchell A R, Furnis B S, Hannaford A J, Smith P W G. Vogel's Textbook of Practical Organic Chemistry. 5th ed. Harlow, Essex, UK: Addison Wesley Longman, 1989. 1034

[32] Deng G S, Ren T G. Synth Commun, 2003, 33: 2995

[33] Wang L M, Sheng J, Tian H, Han J W, Fan Z Y, Qian C T. Synthesis, 2004: 3060

[34] Tanaka K, Toda F. Chem Rev, 2000, 100: 1025

[35] Cao Y Q, Dai Z, Zhang R, Chen B H. Synth Commun, 2005, 35: 1045

[36] Huang D F, Wang J X, Hu Y L, Zhang Y M, Tang J. Synth Commun, 2002, 32: 971

[37] Fuentes A, Marinas J M, Sinisterra J V. Tetrahedron Lett, 1987, 28: 4541

[38] Li J T, Chen G F, Wang J X, Li T S. Synth Commun, 1999, 29: 965

[39] Li J T, Yang W Z, Wang S X, Li S H, Li T S. Ultrason Sonochem, 2002, 9: 237

[40] Perozo-Rondón E, Martín-Aranda R M, Casal B, Durán-Valle C J, Lau W N, Zhang X F, Yeung K L. Catal Today, 2006, 114: 183

[41] Hathaway B A. J Chem Educ, 1987, 64: 367

[42] Nakano T, Irifune S, Umano S, Inada A, Ishii Y, Ogawa M. J Org Chem, 1987, 52: 2239

[43] Sutton R C, Thai L, Hewitt J M, Voycheck C L, Tan J S. Macromolecules, 1988, 21: 2432

[44] Hagiwara H, Inoguchi H, Fukushima M, Hoshi T, Suzuki T. Tetrahedron Lett, 2006, 47: 5371

[45] Srivastava R. J Mol Catal A, 2007, 264: 146

[46] Shirini F, Khaligh N G. J Iran Chem Soc, 2012, 9: 495

[47] Khaligh N G, Shirini F. J Mol Catal A, 2011, 348: 20

[48] Khaligh N G. Tetrahedron Lett, 2012, 53: 1637

[49] Khaligh N G. RSC Adv, 2012, 2: 3321

[50] Khaligh N G. Catal Sci Technol, 2012, 2: 2211

[51] Khaligh N G. J Mol Catal A, 2012, 363-364: 90
[52] Shirini F, Khaligh N G, Jolodar O G. J Iran Chem Soc, 2013, 10: 181

[53] Khaligh N G. RSC Adv, 2012, 2: 12364

[54] Khaligh N G. RSC Adv, 2013, 3: 99

[55] Chapiro A, Mankowski Z. Eur Polym J, 1988, 24: 1019

[56] Cabot B, Deratani A, Foissy A. Colloids Surf A, 1998, 139: 287

[57] Brandrup J, Immergut E H, Grulke E. Polymer Handbook. 4th ed. New York: Wiley, 1999. Sec VII

[58] Watanabe K, Imazawa A. Bull Chem Soc Jpn, 1982, 55: 3208

[59] Salehi P, Khodaei M M, Zolfigol M A, Keyvan A. Monatsh Chem, 2002, 133: 1291

[60] Irie K, Watanabe K. Bull Chem Soc Jpn, 1980, 53: 1366

[61] Zheng M, Wang L C, Shao J G, Zhong Q. Synth Commun, 1997, 27 : 351

[62] Yadav J S, Reddy B V S, Nagaraju A, Sarma J A R P. Synth Commun, 2002, 32: 893

[63] Huitric A C, Kumler W D. J Am Chem Soc, 1956, 78: 614

[64] Iranpoor N, Kazemi F. Tetrahedron, 1998, 54: 9475

[65] Iranpoor N, Zeynizadeh B, Aghapour A. J Chem Res (S), 1999: 554

[66] Garland C E, Reid E E. J Am Chem Soc, 1925, 47: 2333

[67] Nakano T, Irifune S, Umano S, Inada A, Ishii Y, Ogawa M. J Org Chem, 1987, 52: 2239

[68] Calvino-Casilda V, López-Peinado A J, Martín-Aranda R M, Ferrera-Escudero S, Durán-Valle C J. Carbon, 2004, 42: 1363

[69] Mason T J, Lorimer J P, Mistry B P. Tetrahedron, 1985, 41: 5201

[70] Zeng X F, Ji S J, Wang S Y. Tetrahedron, 2005, 61: 10235

[71] Doktycz S J, Suslick K S. Science, 1990, 247: 1067

[72] Wang L M, Sheng J, Tian H, Han J W, Fan Z Y, Qian C T. Synthesis, 2004, 18: 3060

[73] Bao W L, Zhang Y M, Ying T K. Synth Commun, 1996, 26: 503

[74] Zhang X Y, Fan X S, Niu H Y, Wang J J. Green Chem, 2003, 5: 267

[75] Li J J, Su W K, Li N. Synth Commun, 2005, 35: 3037

[76] Habibi A, Sheikhhosseini E, Bigdeli M, Balalaie S, Farrokhi E. Int J Org Chem, 2011, 1: 143

[77] Sarda S R, Jadhav W N, Bhusare S R, Wasmatkar S K, Dake S A, Pawar R P. Int J ChemTech Res, 2009, 1: 265

[78] Teimouri F, Hadi Khezri S, Miri Z, Eftekhari-Sis B, Azizian J.J Sci I A U (JSIAU), 2009, 19: 103

[79] Sebti S, Solhy A, Tahir R, Smahi A. Appl Catal A, 2002, 235: 273

[80] Zeng H Y, Yin S F, Li Y. Chin J Org Chem, 2007, 27: 528 